\title{
PERANCANGAN MASSIVELY MULTIPLAYER ONLINE KNIGHTS FANTASY ONLINE
}

\author{
Darius Andana Haris ${ }^{1}$, Viny Christanti $\mathbf{M}^{2}$, Davin Pratama ${ }^{3}$ \\ 1,2, Program Studi Teknik Informatika Fakultas Teknologi Informasi Universitas Tarumanagara \\ ${ }^{3}$ Catlil Game Studio Jl. Arteri Pos Pengumben No. 8, Jakarta \\ Jl. Let. Jend. S. Parman No. 1, Jakarta 11440 Indonesia
}

\begin{abstract}
Abstrak
Knights Fantasy Online adalah game online multiplayer dengan genre role-playing. Game ini dibuat menggunakan ActionScript 3.0 dengan Adobe Flash sebagai sisi klien dan Java sebagai servernya. Desain dari game ini dibuat dengan Adobe illustrator. Dalam game ini, pemain memulai petualangannya di dunia bernama Edenia, sebagai ksatria dari kerajaan yang bernama Aurum. Pemain bertugas mengkontrol jumlah populasi monster. Pemain dapat mengambil quest, mengumpulkan equipment dan meningkatkan ability karakternya.
\end{abstract}

Kata kunci: Knights Fantasy Online, Massively Multiplayer Online Game, RPG, MMORPG

\begin{abstract}
Knights Fantasy Online is a massively multiplayer online game with role-playing game genre. This game will be developed using ActionScript 3.0 of Adobe Flash for client and Java for its server, while the design of the game will be designed using Adobe Illustrator. In this game, Players start their adventure in a world called Edenia as a knight from a kingdom called Aurum, the player is in charge of controlling the population of monsters. Players can take on quests, collect equipment and improve their character's ability.
\end{abstract}

Keywords: Knights Fantasy Online, Massively Multiplayer Online Game, RPG, MMORPG

\section{PENDAHULUAN}

Dewasa ini, game sudah berkembang begitu pesat, game bukan hanya dimainkan untuk melepas penat, namun juga menjadi salah satu sarana komunikasi. Dengan game, para pemain dapat berinteraksi secara virtual seperti halnya dunia nyata. Jenis game yang memiliki unsur ini adalah Massively Multiplayer Online Game (MMOG). Melalui MMOG, para pemain dituntut untuk saling berinteraksi dan bekerja sama untuk mencapai target yang telah ditentukan dalam game tersebut [1].

MMOG sendiri merupakan sebuah game yang dapat dimainkan oleh banyak pemain dari berbagai lokasi dengan menggunakan internet [2]. Pada umumnya, MMOG terkenal berbasis pada tema fantasi, namun beberapa MMOG menggabungkan beberapa tema atau menggantikan elemen fantasi dengan elemen lainnya seperti sains fiksi, pedang dan sihir atau crime fiction. Elemen-elemen ini kemudian dikembangkan menggunakan skenario-skenario seperti quest, monster, dan item [1].

MMOG sangat cocok untuk digunakan sebagai sarana komunikasi, karena pemain dapat menjumpai pemain-pemain lainnya yang berasal dari berbagai lokasi di dunia nyata. Selain itu, MMOG biasanya menyediakan fitur perserikatan yang lebih dikenal dengan sebutan Guild atau Clan [3]. Hal ini tentu membuat interaksi dalam MMOG tidak jauh berbeda dengan interaksi 
yang terjadi di dalam dunia nyata. Kerja sama antar pemain juga dibutuhkan dalam MMOG untuk mencapai objektif yang ada pada game.

Sejak pertama muncul di Indonesia pada tahun 2001, MMOG sampai saat ini masih digandrungi oleh berbagai kalangan [4]. Hal ini disebabkan oleh karena MMOG tidak memandang usia dan waktu sehingga semua orang mempunyai kesempatan yang luas untuk memainkannya. MMOG juga pada umumnya memungkinkan pemain mendapatkan kebebasan untuk mengeksplorasi diri [5].

Game yang dirancang adalah sebuah MMOG dengan unsur Role Playing yang memiliki judul Knights Fantasy Online, judul ini menyiratkan bahwa pemain akan bermain sebagai seorang prajurit yang akan menumpas monster-monster yang ada di dalam dunia game tersebut. Game tersebut akan dirancang dengan menggunakan Adobe Flash untuk bagian klien karena fleksibilitas layer dan tersedianya Socket pada Adobe AIR. Sedangkan pada bagian server akan dirancang dengan menggunakan Java karena Java dapat dijalankan pada berbagai sistem operasi dengan mudah.

Para pemain dapat berpetualang dalam dunia game untuk melawan monster dan melakukan misi-misi yang ada untuk meningkatkan level serta kemampuan dari karakternya hingga maksimal. Selain itu pemain juga dapat mengumpulkan barang-barang dan perlengkapan senjata yang didapatkan dari monster-monster yang ada untuk memperkuat karakter pemain

Monster yang mengisi dunia game akan dikendalikan oleh Artificial Intelligence sehingga dapat bergerak dan merespon serangan pemain ataupun juga langsung menyerang pemain apabila monster tersebut adalah monster yang agresif. Di dalam game juga akan ada NonPlayable Character (NPC), NPC adalah karakter yang tidak dapat digunakan oleh pemain, NPC akan ada untuk memberikan informasi dan juga memberikan misi kepada pemain untuk diselesaikan. Jenis dari misi-misi yang ada pun beragam, misalnya melawan sejumlah monster ataupun mengumpulkan barang. Akhir dari game dicapai apabila karakter pemain mencapai level 50 dan telah menyelesaikan semua misi yang ada di dalam game, namun pemain tetap dapat menjelajahi game tersebut dengan karakternya..

\section{DASAR TEORI}

Dalam perancangan game tentunya memerlukan dasar-dasar teori sebagai fondasi untuk merancangnya. Hal-hal yang perlu dijelaskan adalah metode perancangan, genre game, environment, artificial intelligence, finite state machine, client/server dan beberapa hal lainnya yang berhubungan dengan perancangan game ini.

\subsection{Metode Perancangan}

Sebelum suatu game dibuat, diperlukan metode perancangan yang berguna sebagai patokan dalam proses pembuatan game dan juga menentukan lingkup dari game yang ingin dibuat. Terdapat beberapa hal yang harus diperhatikan dalam proses perancangan game yaitu sebagai berikut [6]:

1. High Concept

High Concept merupakan deskripsi singkat dari game yang dirancang. High concept juga mengarahkan pembuatan game agar tidak melenceng dari rancangan yang sudah ada.

2. Gameplay

Gameplay menjelaskan tentang apa yang dapat dilakukan dalam game dan bagaimana cara untuk melakukannya.

3. Story

Story merupakan rangkuman mengenai alur cerita dari game yang dirancang. 
4. Audience

Audience berisikan tentang sasaran pemain dari game yang dirancang baik itu sasaran usia atau jenis kelamin.

5. Rancangan Tampilan

Rancangan tampilan berisikan gambaran kasar dari tampilan user interface (UI) dari game yang dirancang.

\subsection{Genre Games}

Setiap game tentunya berbeda satu sama lainnya dan masuk kedalam suatu kategori tertentu. Genre game mengkategorikan sebuah game berdasarkan interaksi permainan [7]

Berikut ini adalah beberapa klasifikasi game berdasarkan genre [8]:

1. Adventure

Genre adventure berawal dari game berbasis teks seperti Collosal Cave Adventure. Namun, seiring dengan berkembangnya gaming system, para developer berusaha memasukan visual kedalamnya. Genre game ini sangat diminati karena tantangan dari puzzle solving dan tingkat kekerasan yang rendah. Beberapa contoh dari game dengan genre adventure adalah seri Indiana Jones, King's Quest dan The Walking Dead.

2. Role Playing Game (RPG)

Berkembang dari game pen-and-paper seperti Dungeon and Dragons, RPG adalah sebuah tipe spesial dari game adventure yang biasanya menggabungkan tiga elemen utama yaitu misi yang spesifik, sebuah proses evolusi karakter melalui experience untuk meningkatkan kemampuannya melawan musuh yang lebih kuat dan juga perolehan dan manajemen barangbarang dan inventori untuk misi (contohnya: perlengkapan senjata, makanan dan alat-alat). Walaupun begitu, game-game RPG masih memliki banyak variasi dan tampilan. Contoh game dengan genre RPG adalah Final Fantasy, Suikoden, The Elder Scrolls dan Diablo

\subsection{Client/Server}

Pada dasarnya, sebuah sistem yang berbasis network terdiri atas server, client dan media untuk komunikasi. Sebuah komputer yang menjalankan program yang membuat request (permintaan) disebut sebagai client. Sebuah komputer yang menjalankan program yang menyediakan pelayanan yang diminta disebut sebagai server. Media komunikasi yang digunakan dapat berupa jaringan kabel maupun nirkabel.

Pada umumnya, program yang berjalan pada client membuat permintaan kepada program yang berjalan pada server. Hal ini melibatkan pelayanan jaringan yang disediakan oleh lapisan transpor, yang mana adalah bagian dari tumpukan perangkat lunak internet, biasa disebut sebagai tumpukan (layer) Transport Control Protocol/Internet Protocol (TCP/IP) dan lapisan transpor itu sendiri terbagi atas 2 tipe protokol, yaitu Transmission Control Protocol (TCP) dan User Datagram Protocol (UDP) [9].

\subsection{Transmission Control Protocol (TCP) dan User Datagram Protocol (UDP)}

Transmission Control Protocol (TCP) adalah suatu protokol yang berada di lapisan transport (baik itu dalam tujuh lapis model referensi OSI atau model DARPA) yang berorientasi sambungan (connection-oriented) dan dapat diandalkan (reliable) [10]. TCP umumnya digunakan ketika protokol lapisan aplikasi membutuhkan layanan transfer data yang bersifat andal, yang layanan tersebut tidak dimiliki oleh protokol lapisan aplikasi tersebut. Contoh dari protokol yang menggunakan TCP adalah HTTP dan FTP.

UDP, singkatan dari User Datagram Protocol, adalah salah satu protokol lapisan transpor TCP/IP yang mendukung komunikasi yang tidak andal (unreliable), tanpa koneksi (connectionless) antara host-host dalam jaringan yang menggunakan TCP/IP [11]. UDP sering digunakan pada protokol yang "ringan" (lightweight), untuk menghemat sumber daya memori dan prosesor. 


\subsection{Finite State Machine}

Finite State Machine (FSM) dikenal juga dengan nama Finite State Automation (FSA) adalah sebuah alat, atau model dari alat, yang memiliki sejumlah state (keadaan) dalam suatu waktu dan dapat beroperasi terhadap input untuk membuat transisi dari satu state menuju state lainnya ataupun membuat output atau juga tindakan.

Sebuah FSM hanya dapat berada dalam satu state dalam satu waktu. FSM itu sendiri pada mulanya digunakan oleh matematikawan untuk menyelesaikan persoalan matematika. Salah satu FSM yang terkenal adalah Turing Machine yang dibuat oleh Alan Turing [12].

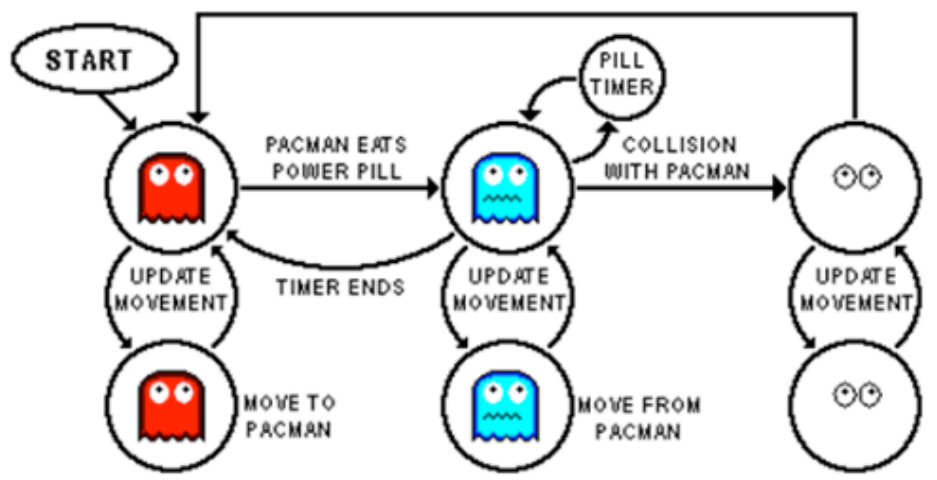

Gambar 1 Ghost Finite State - Pacman

Sumber: oddwiring, Finite State Machines,

http://oddwiring.com/archive/websites/mndev/MSB/GD100/fsm.htm, 24 Agustus 2015.

Salah satu contoh penggunaan FSM dalam game adalah hantu dalam game Pac-Man, dimana hantu tersebut memiliki 2 state yaitu evade (menghindar) dan chase (mengejar). Input dari pemain ketika memakan pil kekuatan adalah kondisi yang mengubah state hantu dari chase menjadi evade dan ketika waktu penggunaan pil tersebut habis, maka state hantu yang ada berubah kembali dari evade menjadi chase [12].

\section{PERANCANGAN}

Game Knights Fantasy Online mempunyai rancangan massively multiplayer online game (MMOG) dan genre dari game tersebut adalah Role Playing Game (RPG) dengan sistem pertempuran Hack and Slash. Game ini dirancang dengan tampilan berbentuk 2 dimensi. Game ini akan terdiri atas dua bagian, yaitu server dan client. Client akan membuat request kepada server dan kemudian server akan memproses data yang telah diminta lalu mengirimkan data kembali kepada client dan ditampilkan oleh client untuk dilihat oleh pemain. Jumlah pemain tidak dibatasi oleh server, namun hal ini bergantung pada kemampuan dari komputer server. Client dari game ini hanya dapat dijalankan pada komputer yang menggunakan sistem operasi minimal Windows 7.

Game ini mengusung genre RPG sehingga tentunya akan memiliki unsur utama RPG yaitu pemain menghidupi karakter yang dimainkan dan menentukan arahan dan tujuan dari karakternya. Game ini juga memiliki sistem open world yaitu sebuah dunia yang mana dapat dijelajahi pemain dengan bebas tanpa adanya batasan. Dunia itu sendiri akan terbagi atas kota, desa, field, ataupun dungeon.

Selain meningkatkan kemampuan karakternya, pemain juga dapat melakukan berbagai kustomisasi dan perubahan terhadap penampilan karakternya. Dalam pembuatan karakter, pemain dapat memilih model dan warna rambut, model mata dan warna pupil mata dan di dalam 
permainan, pemain juga dapat mengganti perlengkapan senjata dan pakaian yang dikenakan oleh karakternya.

\subsection{High Concept}

Game yang dirancang adalah sebuah Massively Multiplayer Online Role Playing Game (MMORPG), dimana pemain dapat membuat karakternya sendiri dan melakukan kustomisasi sesuai keinginannya. MMORPG ini pun tidak hanya berfokus pada pertarungan namun akan disediakan juga misi-misi. Game ini ditujukan bagi anak-anak dengan usia minimal 8 tahun sampai orang dewasa.

\subsection{Gameplay}

Gameplay yang ada dalam perancangan game ini tentunya adalah gameplay umum dari sebuah game RPG yaitu meningkatkan level pemain dengan bertarung melawan monster dan mendapatkan experience point, menjalankan misi-misi yang diberikan oleh NPC dan juga mengumpulkan barang-barang langka yang didapatkan dari monster maupun dibuat melalui Non-Playable Character (NPC). Namun, di dalam game ini juga akan ada beberapa minigame yang dapat dimainkan oleh pemain yang dapat meningkatkan kemampuan dari karakter yang dimiliki.

Sistem pertarungan yang digunakan didalam game ini adalah Hack and Slash, dengan ini pemain dituntut untuk ikut serta dalam melawan monster yang ada karena karakter tidak menyerang secara otomatis melainkan melalui input yang diberikan pemain baik itu input serangan biasa atau penggunaan jurus. Hack and Slash itu sendiri adalah sebuah sistem pertarungan yang secara khusus menyiratkan fokus pada pertarungan dengan senjata jarak dekat atau biasa disebut hand to hand namun tidak menutup kemungkinan untuk ditambahkan senjata jarak jauh. Game ini juga akan menyediakan fitur open world dimana pemain akan dapat menjelajahi dunia game dengan bebas.

Dalam dunia game, para pemain dapat saling bertemu dan juga berinteraksi satu sama lain dengan fitur chat. Selain itu, para pemain juga dapat bersama-sama berpetualang melawan monster dan juga melakukan misi.

\subsubsection{Desain Kontrol}

Kontrol yang digunakan dalam game Knights Fantasy Online adalah mouse dan keyboard. Mouse digunakan untuk melakukan navigasi untuk mengakses menu-menu yang ada dalam game, yaitu menu inventory, equip, status, skill, dan quit. Keyboard digunakan untuk menggerakan karakter yang dimiliki, berinteraksi dengan objek-objek yang ada di dalam game, dan beberapa fungsi lainny

Tabel 1 Rancangan tombol keyboard

\begin{tabular}{|l|l|l|l|l|}
\hline Tombol & Fungsi & & Tombol & Fungsi \\
\hline Panah Atas & $\begin{array}{l}\text { Menggerakkan karakter ke } \\
\text { atas }\end{array}$ & $\mathrm{Z}$ & $\begin{array}{l}\text { Berinteraksi dengan Non-Playable Character } \\
(N P C)\end{array}$ \\
\hline $\begin{array}{l}\text { Panah } \\
\text { Bawah }\end{array}$ & $\begin{array}{l}\text { Menggerakkan karakter ke } \\
\text { bawah }\end{array}$ & $\mathrm{X}$ & Mengambil barang yang ada di tanah \\
\hline Panah Kiri & Menggerakkan karakter ke kiri & & Enter & Mengaktifkan chatbox \\
\hline $\begin{array}{l}\text { Panah } \\
\text { Kanan }\end{array}$ & $\begin{array}{l}\text { Menggerakkan karakter ke } \\
\text { kanan }\end{array}$ & $1 \sim 9$ & $\begin{array}{l}\text { Mengaktifkan hotkey yang sudah diatur oleh } \\
\text { pemain }\end{array}$ \\
\hline Spasi & Melakukan serangan & $\mathrm{Z}$ & $\begin{array}{l}\text { Berinteraksi dengan Non-Playable Character } \\
\text { (NPC) }\end{array}$ \\
\hline
\end{tabular}




\subsubsection{Desain Karakter}

Desain karakter yang ada didalam game Knights Fantasy Online akan terbagi menjadi tiga yaitu karakter yang dimiliki oleh masing-masing pemain, Non-Playable Character (NPC) dan juga monster. Perincian tentang desain karakter dalam game adalah sebagai berikut:

\section{Karakter Pemain}

Penampilan dari karakter yang dimiliki oleh masing-masing pemain juga dapat dikustomisasi saat pemain membuat karakter baru dan di dalam permainan. Pemain dapat memilih model rambut, warna rambut, model mata dan warna mata. Tentunya karakter yang ada juga akan dibedakan sesuai dengan jenis kelamin yang dipilih oleh pemain saat pembuatan akun.

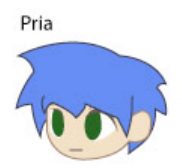

(1)

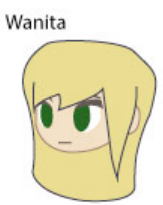

(1)

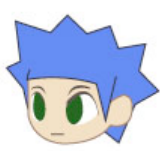

(2)

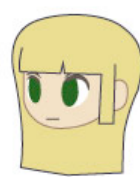

(2)

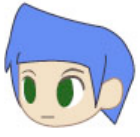

(3)

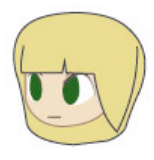

(3)

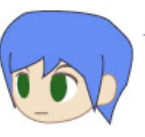

(4)

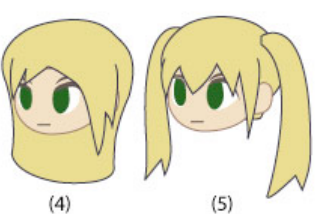

(5)

Gambar 2. Desain model rambut karakter pemain

Karakter milik pemain akan memiliki tingkatan atau disebut juga level untuk meningkatkan level, karakter dapat mengumpulkan experience point yang didapat dengan mengalahkan monster ataupun mengerjakan misi.

Karakter milik pemain juga akan memiliki kemampuan yang diukur melalui status karakter.

Status karakter akan terdiri dari dua bagian yaitu:

a) Status Dasar

Status dasar terdiri dari beberapa atribut yaitu STR (Strength), AGI (Agility), VIT (Vitality), DEX (Dexterity), dan LUK (Lucky) yang akan mendasari kemampuan karakter dan memiliki nilai awal 1 poin dan nilai maksimal 99 poin. Status dasar dapat ditingkatkan apabila karakter memiliki status point yang didapatkan ketika level dari karakter tersebut meningkat. Status point yang didapat untuk setiap kali level karakter meningkat adalah 2 poin.

b) Status Tarung

Status tarung merupakan hasil kalkulasi dari status dasar dan status tambahan yang didapat dari perlengkapan senjata. Status tarung yang akan menentukan besarnya serangan dan pertahanan yang dimiliki oleh karakter pemain.

Tabel 2. Status tarung karakter pemain

\begin{tabular}{|c|c|c|c|}
\hline Status & Kalkulasi & Status & Kalkulasi \\
\hline Health Point & Level $* 50+\left(\operatorname{VIT}^{*} 15\right)$ & Evasion & $\mathrm{AGI} * 2$ \\
\hline Stamina Point & Level $* 20+(\mathrm{STR} * 10)$ & Accuracy & $\mathrm{DEX} * 2$ \\
\hline Attack & $(\mathrm{STR} * 2)+(\mathrm{DEX} / 4)+$ Weapon Attack & Critical & LUK + (DEX / 5) \\
\hline Defense & VIT + Equipment Defense & $\begin{array}{l}\text { Attack } \\
\text { Speed }\end{array}$ & $\begin{array}{l}100+(\mathrm{AGI} / 2)+(\mathrm{DEX} \\
/ 5)\end{array}$ \\
\hline
\end{tabular}

Contoh simulasi perhitungan pada salah satu status tarung adalah sebagai berikut, dengan rumus perhitungan untuk health point (HP) adalah 


$$
H P=(\text { level } * 50)+(\text { VIT } * 15)
$$

Saat karakter level 2 dengan 2 status point yang didistribusikan pada status VIT sehingga nilainya menjadi 3 poin maka perhitungannya adalah sebagai berikut

$$
H P=(2 * 50)+(3 * 15)=145
$$

Maka health point yang akan dimiliki oleh karakter pada level 2 dengan 3 poin VIT adalah 145.

Selain status, karakter pemain juga memiliki jurus yang disebut skill. Skill dapat ditingkatkan apabila karakter pemain memiliki skill point. Sama seperti status point, skill point didapatkan setiap kali level karakter meningkat, namun skill point yang didapat hanyalah 1 poin. Skill sendiri terdiri dari dua bagian yaitu:

a) Skill Pasif

Merupakan skill yang dapat meningkatkan status dasar ataupun status tarung dari karakter pemain. Skill jenis ini memiliki efek permanen terhadap karakter pemain.

Tabel 3 Contoh skill pasif

\begin{tabular}{|l|l|c|}
\hline Nama Skill & Efek Skill & Level Maksimal \\
\hline Sword Mastery & Meningkatkan serangan senjata pedang $(5 *$ level skill $)$ & 10 \\
\hline Shield Mastery & Meningkatkan pertahanan perisai $(5 *$ level skill $)$ & 10 \\
\hline
\end{tabular}

Contoh-contoh simulasi perhitungan pada salah satu skill pasif adalah sebagai berikut, Skill Sword Mastery meningkatkan serangan (attack) senjata pedang dan rumus perhitungan peningkatannya adalah

$$
\text { Attack }+=5 * \text { level skill }
$$

Apabila karakter memiliki skill Sword Mastery level 10 maka hasil perhitungannya adalah

$$
\text { Attack }+=5 * 10=50
$$

Maka skill Sword Mastery level 10 meningkatkan nilai attack dari karakter sebesar 50 poin apabila menggunakan senjata pedang. Perhitungan ini tidak berlaku apabila karakter tidak menggunakan senjata berjenis pedang, misalnya tangan kosong atau tanpa senjata.

b) Skill Aktif

Skill aktif adalah jenis skill yang dapat digunakan oleh karakter pemain untuk membantu mengalahkan monster. Skill aktif juga dapat di tempatkan pada slot hotkey untuk mempermudah penggunaannya.

Tabel 4 . Contoh skill aktif

\begin{tabular}{|l|l|l|l|}
\hline $\begin{array}{l}\text { Nama } \\
\text { Skill }\end{array}$ & Pemakaian SP & Efek Skill & $\begin{array}{l}\text { Level } \\
\text { Maksimal }\end{array}$ \\
\hline Bash & $10+5 *$ level skill & Menyerang lawan $(300 \%+15 \% *$ level skill $)$ & 10 \\
\hline Charge & $15+7 *$ level skill & $\begin{array}{l}\text { Menyerang }(150 \%+30 \% * \text { level skill }) \text { dan mendorong } \\
\text { lawan }(5 * \text { level skill })\end{array}$ & 5 \\
\hline
\end{tabular}

Contoh simulasi perhitungan pada salah satu skill pasif adalah sebagai berikut, Skill Bash memiliki rumus dasar sebagai berikut:

Damage $=(300 \%+15 \% *$ level skill $) *$ attack 
Dimana status attack karakter diambil sebagai perhitungan dasar serangan, apabila diambil contoh karakter pada level 2 dengan 2 status point yang didistribusikan pada status STR dan karakter tersebut mengenakan senjata Wooden Sword sehingga memiliki status attack sebesar 21, maka nilai serangan skill Bash level 10, maka nilai serangannya dengan pembulatan adalah sebagai berikut:

$$
\text { Damage }=(300 \%+15 \% * 10) * 21=95
$$

Maka total serangan apabila karakter menggunakan skill Bash level 10 adalah 95.

\section{Non-Playable Character}

Non-Playable Character (NPC) adalah karakter yang tidak dapat dipakai untuk dimainkan oleh pemain. Pemain dapat berinteraksi dengan NPC untuk mendapatkan misi, membeli barang ataupun mendapatkan petunjuk. Namun ada juga NPC yang hanya berperan sebagai figuran dan tidak memberikan dampak bagi pemain. Saat melakukan interaksi dengan NPC, pada layar pemain akan muncul kotak dialog yang menampilkan pesan dari NPC tersebut.

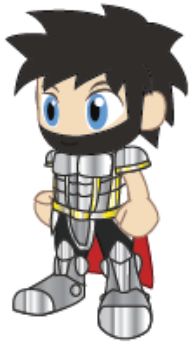

Knight Ellgar

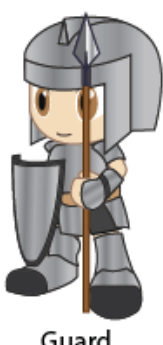

Guard

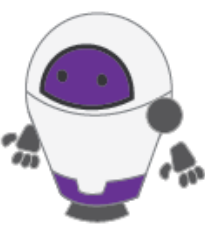

F-TIUNTAR

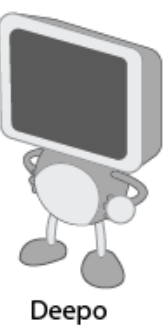

Deepo

Gambar 3. Contoh tampilan NPC

Desain dari NPC sendiri akan ada yang mirip seperti karakter pemain dengan berbagai pakaian dan fitur-fitur wajah yang dibuat secara khusus, namun ada juga NPC yang berbentuk seperti sebuah objek.

\section{Monster}

Monster didalam game ini akan muncul dalam field ataupun dungeon. Pemain dapat melawan monster-monster yang ada untuk mendapatkan experience point dan juga barangbarang. Monster yang ada juga dapat menyerang dan mengalahkan karakter pemain apabila monster tersebut diserang. Ada juga beberapa monster yang berjenis agresif dan langsung menyerang karakter pemain saat melihatnya.

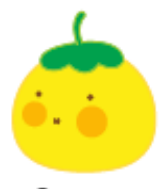

Orange

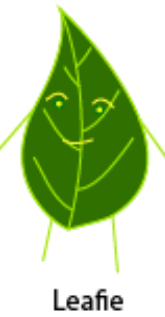

Leafie

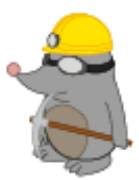

Mole

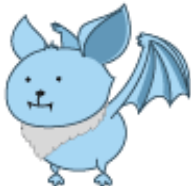

Blue Bat

Gambar 4. Contoh tampilan monster

Monster yang ada juga akan memiliki kemampuan untuk menyeimbangkannya dengan kemampuan yang dimiliki karakter pemain. Sama halnya seperti karakter pemain, monster juga memiliki status dasar yaitu STR, AGI, VIT, DEX dan LUK tetapi status tarung yang dimiliki sudah ditentukan dari awal dan tidak dilakukan kalkulasi seperti karakter pemain, 
melainkan status dasar hanya berpengaruh terhadap kalkulasi akhir serangan ataupun pertahanan. Selain itu monster juga akan menjatuhkan barang apabila telah dikalahkan oleh pemain, barang yang dijatuhkan juga telah ditetapkan sejak awal. Barang yang dijatuhkan oleh monster tidak terbatas hanya 1 barang saja, namun monster tersebut dapat menjatuhkan keseluruhan barang yang telah ditetapkan tetapi barang yang dijatuhkan tetap tergantung pada drop rate (kemungkinan barang tersebut untuk jatuh) dari barang tersebut.

\subsubsection{Desain Objek}

Objek dalam game Knights Fantasy Online berupa barang-barang yang bisa dibeli melalui NPC ataupun barang yang dijatuhkan oleh monster yang sudah dikalahkan oleh pemain. Barang-barang tersebut terbagi menjadi tiga jenis yaitu useable item, equipment dan miscellaneous. Perincian dari setiap jenis barang tersebut adalah sebagai berikut:

1. Useable Item

Useable Item adalah jenis barang yang dapat digunakan untuk memberikan efek-efek tertentu bagi karakter pemain.

\section{Equipment}

Equipment adalah jenis barang atau perlengkapan yang dapat dikenakan oleh karakter pemain dan dapat meningkatkan kemampuan karakternya. Tetapi tidak semua perlengkapan tersebut akan meningkatkan kemampuan pemain secara drastis, akan ada juga perlengkapan yang hanya bersifat dekorasi bagi karakter pemain. Kemampuan karakter yang ditingkatkan oleh equipment dengan jenis weapon adalah attack dan kemampuan yang ditingkatkan oleh equipment dengan jenis shield, headgear, armor, pants, gloves dan shoes adalah defense.

3. Miscellaneous

Miscellaneous adalah jenis barang yang tidak dapat digunakan dan juga tidak dapat dikenakan oleh karakter pemain. Kegunaan dari barang-barang miscellaneous adalah untuk dijual dan juga dikumpulkan untuk misi-misi tertentu.

\subsubsection{Desain Level}

Desain level dalam game ini terbagi menjadi dua yaitu desain dunia dan desain misi. Perinciannya adalah sebagai berikut:

1. Desain Dunia

Dunia didalam game Knights Fantasy Online dapat diakses dengan bebas oleh pemain. Dunia itu sendiri tersusun atas kota dan juga field/dungeon yang masing-masing akan memiliki tema-tema tersendiri misalnya hutan, gua dan lainnya.

Setiap kota dan field/dungeon juga akan terbagi kedalam bagian-bagian yang disebut map dan akan dihubungkan oleh sebuah gerbang yang disebut warp portal.

2. Desain Misi

Dalam game ini akan terdapat berbagai macam misi yang dapat diambil dan dikerjakan oleh pemain dan akan memberikan berbagai hal, misalnya experience point ataupun barang kepada karakter pemain sebagai bayarannya apabila misi tersebut diselesaikan dengan baik.

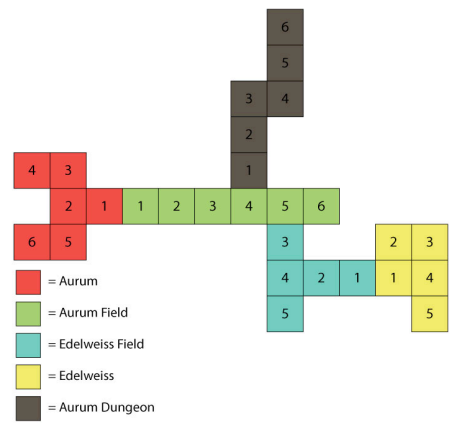

Gambar 5. Desain peta dunia 


\subsubsection{Story}

Latar belakang cerita pada game ini bermula pada sebuah dunia yang bernama Edenia di masa lalu dan hiduplah seorang penyihir yang memiliki kekuatan untuk mengubah benda mati menjadi makhluk hidup. Pada awalnya para makhluk hidup itu sangat bersahabat dan membantu hidup manusia.

Suatu saat sang penyihir meninggal namun kekuatannya tetap tinggal dalam dunia tersebut dan justru semakin kuat dan terus merubah benda-benda didalam dunia tersebut menjadi makhluk hidup selain itu juga binatang-binatang yang hidup dalam dunia tersebut mulai berubah menjadi lebih besar dari sebelumnya. orang-orang mulai mengkategorikan makhlukmakhluk tersebut sebagai monster karena beberapa dari mereka tidak dapat dikendalikan dan menyerang manusia. Oleh karena itu raja-raja di dunia tersebut memerintahkan tentaranya untuk memperbanyak pasukan pertahanannya dan menumpas monster-monster yang ada.

Dalam game ini pemain berperan sebagai seorang pemuda/pemudi yang mendaftarkan dirinya untuk masuk ke dalam pasukan pertahanan dan membantu pasukan tersebut mengendalikan populasi monster.

\subsubsection{Audience}

Game ini diperuntukkan bagi segala kalangan dan jenis kelamin, tetapi dianjurkan bagi pemain dengan usia minimal 8 tahun atau paling tidak dapat membaca dan juga menulis karena akan ada tulisan-tulisan yang perlu dibaca dan juga karena tersedianya sistem chatting.

\subsubsection{Rancangan Tampilan}

Rancangan tampilan dalam game Knights Fantasy Online terbagi menjadi beberapa bagian yaitu rancangan modul login, rancangan modul pemilihan karakter, rancangan modul pembuatan karakter dan rancangan modul permainan. Rancangan modul permainan sendiri akan terbagi atas rancangan window inventory, rancangan window equip, rancangan window status, rancangan window skill, rancangan window option, rancangan window quit dan rancangan window respawn. Penjelasan tentang rancangan tampilan yang ada adalah sebagai berikut:

1. Tampilan Modul Login

Tampilan pada modul login dapat dilihat pada saat game dimulai. Dalam modul login ini akan ada logo dari game Knights Fantasy Online pada bagian atas tengah layar permainan dan juga diikuti oleh login box tepat di bawah logo tersebut. Pemain dapat melakukan input data akun lalu masuk ke dalam game, membuat akun baru ataupun keluar dari game.

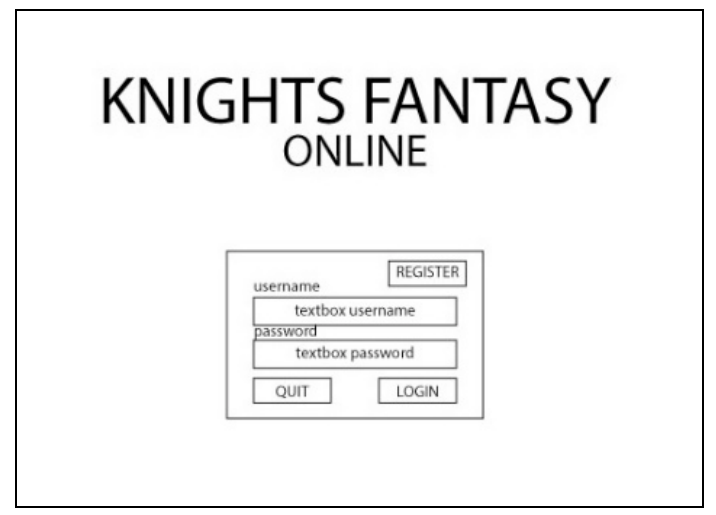

Gambar 6. Tampilan modul login

2. Tampilan Modul Pemilihan Karakter

Setelah pemain melakukan login berikutnya pemain akan dibawa menuju modul pemilihan karakter. Dalam modul pemilihan karakter ini akan ada tiga slot karakter dan akan muncul 
nama dan level dari karakter yang dipilih oleh pemain. Tombol new char dapat ditekan apabila pemain belum memiliki karakter pada slot yang dipilih untuk membuat karakter baru, namun apabila pemain sudah memiliki karakter pada slot tersebut, tombol tersebut berubah menjadi tombol let's play, yaitu tombol untuk memulai permainan.

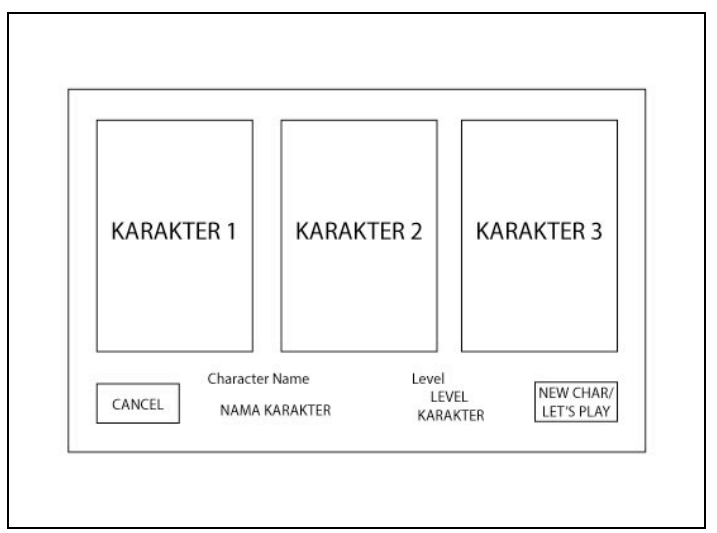

Gambar 7 . Tampilan modul pemilihan karakter

3. Tampilan Modul Pembuatan Karakter

Modul pembuatan karakter muncul apabila pemain memilih untuk membuat karakter baru. Dalam modul ini pemain dapat mengkustomisasi karakter yang ingin dibuat dan hasil kustomisasi langsung tampil disebelah kiri dari pilihan-pilihan yang ada. Pemain dapat memilih model rambut dan mata dengan mengklik tombol panah kiri ataupun tombol panah kanan dan untuk warna rambut dan warna pupil mata dapat dipilih dengan color picker yang disediakan. Kemudian pemain juga dapat memasukan nama karakternya sesuai dengan keinginannya. Tersedia juga tombol cancel untuk membatalkan pembuatan karakter dan tombol let's play untuk menyimpan karakter yang sudah dibuat oleh pemain dan memulai permainan.

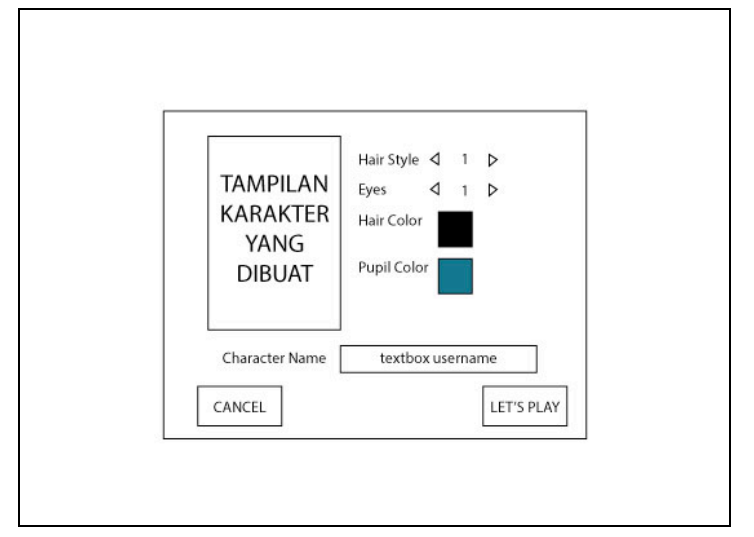

Gambar 8. Tampilan modul pembuatan karakter

4. Tampilan Modul Permainan

Tampilan ini muncul setelah pemain memilih karakter yang akan dipakai untuk bermain. Pada modul ini pemain dapat melihat informasi karakternya dipojok kiri atas, informasi yang ditampilkan ialah level, nama karakter, health point, stamina point dan experience point dari karakter tersebut. Kemudian pemain juga dapat melihat dan mengirim pesan melalui chat box di pojok kiri bawah. Tepat dibawah chat box terdapat tombol-tombol untuk membuka window inventory, window equip, window status, window skill, window option dan window 
quit. Pemain juga dapat mengatur hotkey dipojok kanan bawah. Terdapat sembilan slot untuk hotkey yang dapat diatur oleh pemain.

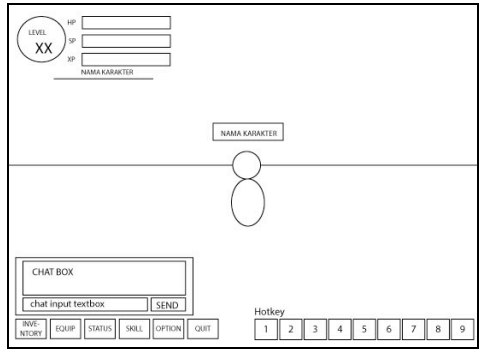

Gambar 9. Tampilan modul permainan

a. Tampilan Window Inventory

Window inventory menampilkan barang yang dimiliki oleh karakter pemain. Window inventory sendiri terbagi atas tiga kompartemen yang masing-masing terdiri dari tiga puluh enam slot. Informasi tentang uang yang dimiliki oleh karakter pemain juga ditampilkan pada window ini.

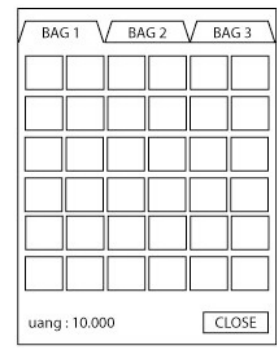

Gambar 10. Tampilan window inventory

b. Tampilan Window Equip

Pada window equip, pemain dapat melihat perlengkapan senjata yang dikenakan oleh karakternya. Pada window ini juga ditampilkan karakter pemain setelah mengenakan perlengkapan senjata.

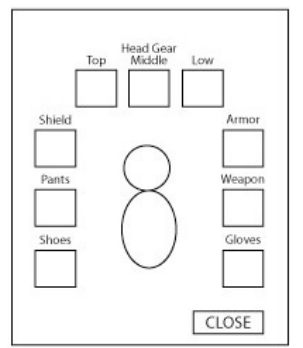

Gambar 11. Tampilan window equip

c. Tampilan Window Status

Pada window ini akan ditampilkan status dari karakter pemain. Pemain juga dapat meningkatkan status dari karakternya pada window ini. Rancangan tampilan

\begin{tabular}{llll|}
\hline STR & 1 & Atk & $1 \sim 10$ \\
AGI & 1 & Def & 1 \\
VIT & 1 & Eva & 1 \\
DEX & 1 & Acc & 1 \\
LUK & 1 & Crit & 1 \\
Status Point: 0 & & Aspd & 100 \\
\hline \multicolumn{2}{l|}{ ClOSE } \\
\hline
\end{tabular}

Gambar 12. Tampilan window status 
d. Tampilan Window Skill

Pada window ini, pemain dapat melihat dan meningkatkan level dari jurus karakternya. Pemain juga dapat mengarahkan kursor pada jurus yang ingin dilihat deskripsinya.

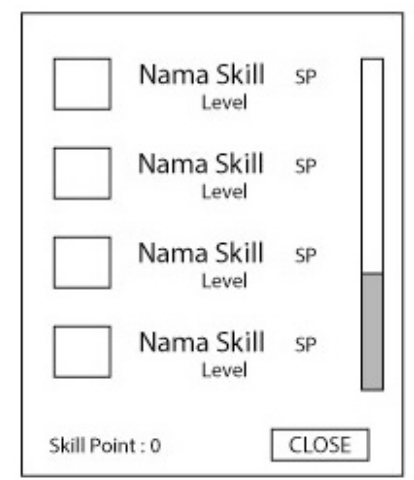

Gambar 13. Tampilan window skill

e. Tampilan Window Option

Pada window ini akan ada scroll bar horizontal untuk mengatur volume suara BGM dan juga SE.

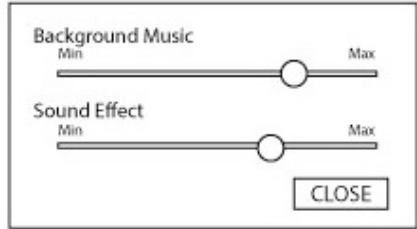

Gambar 14. Tampilan window option

f. Tampilan Window Quit

Dalam window quit akan tersedia tombol quit untuk keluar dari permainan, tombol to title untuk kembali ke modul pemilihan karakter dan tombol cancel untuk menutup window quit

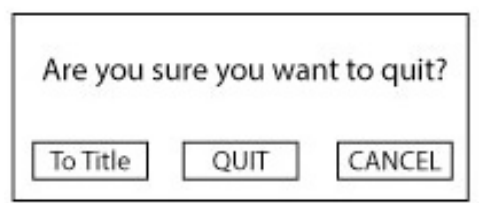

Gambar 15. Tampilan window quit

g. Tampilan Window Respawn

Dalam window respawn akan tersedia tombol respawn untuk mengembalikan karakter ke kota dimana posisinya disimpan dan tombol cancel untuk menutup window respawn.

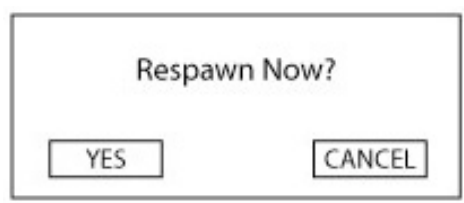

Gambar 16. Tampilan window respawn

\subsubsection{Rancangan Finite State Machine}

Finite State Machine (FSM) digunakan untuk mengatur Behaviour (Kelakuan) dari Artificial Inteligence (AI) yang mengendalikan monster dalam game Knights Fantasy Online. Monster yang ada terbagi atas 2 jenis yaitu monster pasif dan monster agresif. 
FSM dari monster pasif memiliki state awal yaitu idle (diam), Waktu idle ditentukan secara acak dan apabila waktu tersebut habis, maka monster akan memasuki state walk (berjalan). Dalam state walk, monster akan menentukan arah tujuan secara acak dan berjalan menuju posisi tersebut dan apabila monster sudah mencapai posisi yang dituju, monster akan kembali memasuki state idle. Dalam state idle atau walk, apabila karakter pemain menyerang monster tersebut ataupun apabila monster tersebut agresif dan melihat karakter pemain dalam jarak pandangnya, maka monster tersebut akan memasuki state attack (menyerang). Monster akan terus ada dalam state attack sampai karakter pemain yang diserang telah kalah ataupun berpindah map, kemudian monster akan kembali memasuki state idle.

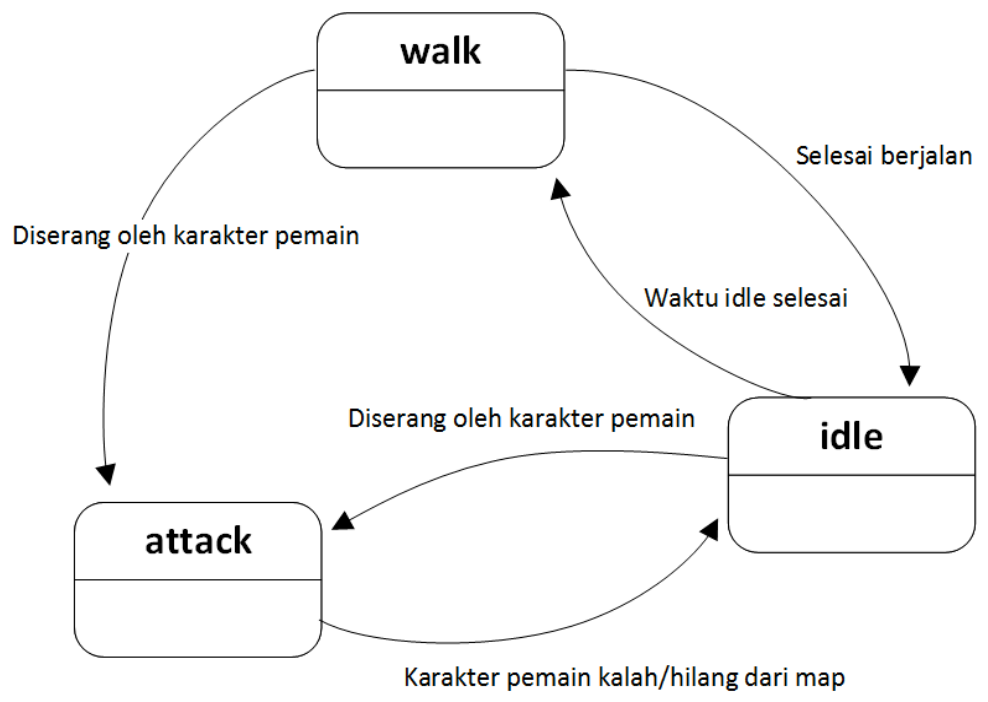

Gambar 17. Finite State Machine monster pasif

Monster agresif tidaklah jauh berbeda dengan monster pasif, hal yang membedakannya adalah monster tersebut tidak menunggu serangan dari pemain untuk berubah dari state idle ataupun state walk menjadi state attack, melainkan apabila monster tersebut melihat karakter pemain, maka monster tersebut akan langsung memasuki state attack.

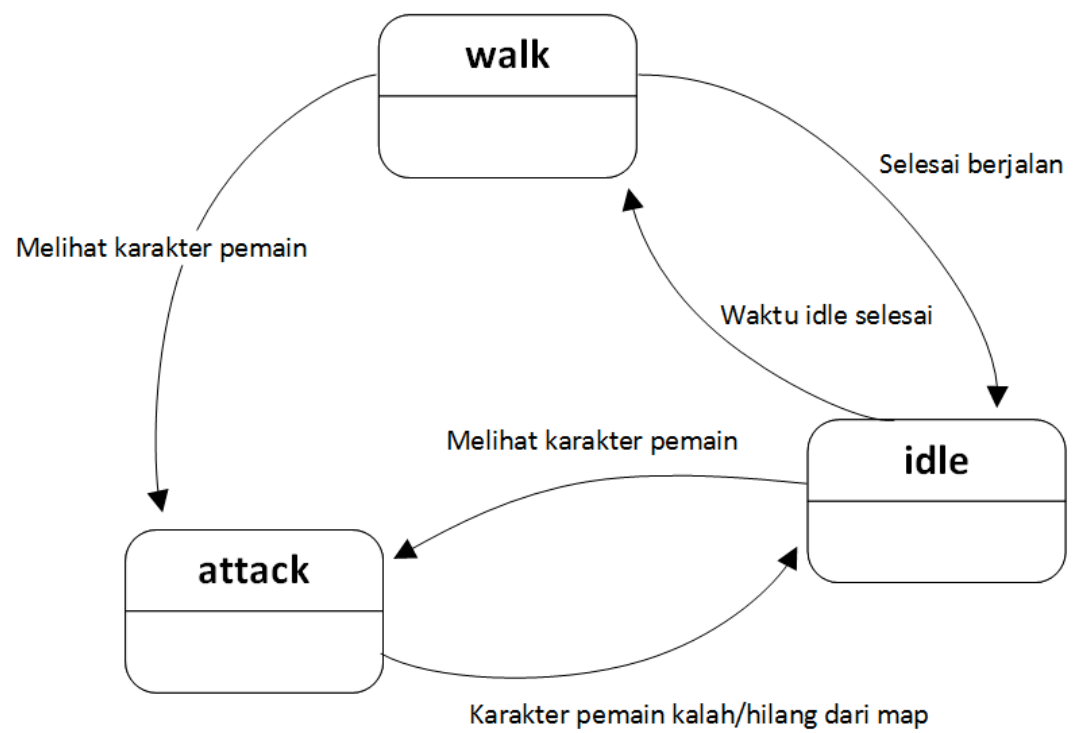

Gambar 18. Finite State Machine monster agresif 


\section{FUTURE WORKS}

Pengembangan game ini berikutnya akan dimulai dari merealisasikan rancangan. Lalu dilanjutkan dengan implementasi server side - client side dalam hal ini akan dilakukan pengujian stress test untuk mendapatkan jumlah pemain yang dapat bermain sekaligus dan juga game balance test untuk melihat apakah permainan sudah seimbang antara musuh dan pemain, apalagi dalam permainan $M M O R P G$ yang memiliki banyak pemain sekaligus seperti ini.

\section{DAFTAR PUSTAKA}

[1] Akil Ar-Raqib dan Edward Mozley Roche, Virtual Worlds Real Terrorism, New York: Barraclough Ltd., 2010, h. 12.

[2] Techopedia, What is Massively Multiplayer Online Game (MMOG)? - Definition from Techopedia, http://www.techopedia.com/definition/27054/massively-multiplayer-online-game-mmog, 12 Agustus 2015.

[3] Chris Yang, Apakah arti guild dalam game online? - Gamexeon.com, http://www.gamexeon.com/artikel/58926/apakah-arti-guild-dalam-game-online, 20 Agustus 2015.

[4] Edel, VGI - Sejarah Game Online di Indonesia, http://vgi.co.id/site/pages/read/05/2015/sejarahgame-online-di-indonesia-1902, 20 Agustus 2015.

[5] Ardanareswari Ayu Pitaloka, Perilaku Konsumsi Game Online Pada Pelajar, http://download.portalgaruda.org/article.php?article=108266\&val=4071, 20 Agustus 2015.

[6] Bob Bates, Game Design Second Edition, Stamford: Cengage Learning PTR, 2004, h. 204.

[7] Ernest Adams, Gamasutra - The Designer's Notebook: Sorting Out the Genre Muddle, http://www.gamasutra.com/view/feature/132463/the_designers_notebook_sorting_php, 22 Agustus 2015.

[8] Ted Stahl, Video Game Genres, http://www.thocp.net/software/games/reference/genres.htm, 22 Agustus 2015.

[9] Rajkumar Buyya, Thamarai S. Somasundaram dan Xingchen Chu, Object Oriented Programming with Java: Essentials and Applications, New Delhi: McGraw-Hill Education, 2005, h. 347.

[10] Information Sciences Institute, Transmission Control Protocol, Los Angeles: University of Southern California, 1981, h. 1.

[11] Information Sciences Institute, User Datagram Protocol, Los Angeles: University of Southern California, 1980, h. 1.

[12] Mat Buckland, Programming Game AI by Example, Texas: Wordware Publishing, 2005 h. 44. 